\title{
THE IMPORTANCE OF PPE USE IN CIVIL CONSTRUCTION: CASE STUDY
}

\section{Rafael Amilton Leite Colares ${ }^{1}$, David Barbosa de Alencar ${ }^{2}$, Jorge de Almeida Brito Junior ${ }^{3}$, Jhonathan Carvalho da $\mathrm{Cruz}^{4}$ and Camily Murrieta Vasconcelos Oliveira Bezerra ${ }^{5}$}

\author{
1, 2, 3 Braulo Cardoso de Mattos Higher Education Institute - FASERRA. Manaus-Amazonas, Brazil. \\ ${ }^{4}$ Nilton Lins University. Manaus-Amazonas, Brazil. \\ ${ }^{5}$ Galileo Institute of Technology and Education of the Amazon - ITEGAM. Manaus-Amazonas, Brazil.
}

Email: leafar.cad@gmail.com, david002870@hotmail.com,jorge.brito@itegam.org.br, jhonnc.cruz@gmail.com, camilymv@hotmail.com

Received: Aug 30th 2019

Accepted: Aug 30th 2019

Published: December 02 ${ }^{\text {th }}, 2019$

Copyright (C2016 by authors and Galileo Institute of Technology and Education of the Amazon (ITEGAM).

This work is licensed under the Creative Commons Attribution International License (CC BY 4.0).

https://creativecommons.org/licen ses/by/4.0/

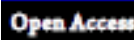

\begin{abstract}
This work of completion aimed to demonstrate the importance of the use of PPE in construction with awareness and guiding the use of personal protective equipment at the construction site area. It is estimated that the construction activity is responsible for many accidents, by requiring its employees to expose themselves to environmental hazards, such as: physical, chemical, biological, ergonomic and accidents. Considering that the Personal Protective Equipment PPE are important security items from working, since, in construction using the same becomes sporadic or non-existent on the part of service providers and employees, even if they have knowledge of the law and standards. During the study we can observe and note that the use of PPE is very important and essential in reducing the risks of accidents during the execution of the activities and their functionality, because the protection of the physical integrity and health of the employee is not isolated behavior, and these must have training and technical guidance on the appropriate use of personal protective equipment. It is understood that the lack of planning of a competent security system can cause occurrences of accidents, causing losses for low productivity and increased costs. Thus, it is evident the importance and prominence that has gained the use of PPE in construction, because this is a topic that has been evolving and requires continuous recycling of professionals in this area.
\end{abstract}

Keywords: Use of PPE; Safety; construction and accident prevention.

\section{INTRODUTION}

Construction, according to the Social Security, is the second sector with the highest number of deaths in work accidents in the country, second only to the area of Road Freight Transport.

Personal protective equipment (PPE) is an important work safety item, and sometimes in civil construction its use becomes commonplace and is not used due to the unwillingness of service providers and employees even though they are aware of the rules and legislation. Many of the labor contractors place little value on the investment and are unaware of the importance of the complexity of choosing appropriate PPE. It also highlights the issues of acceptance, education and awareness of the great importance of safe use and good performance of employee roles, as well as training and the correct instructions for use. This paper aims to demonstrate the importance of using personal protective equipment on the construction site during the execution of activities and their respective functionalities; demonstrating the legal aspects in relation to the worker and the awareness measures that can be used for the best performance of the equipment together with the employee.

Construction companies require their employees to expose themselves to weather and risk factors such as height, drop and projection of materials, repetitive efforts, electricity, heat, often in inappropriate circumstances, without breaks and / or in minimal conditions. work, she becomes responsible for much of the existing accidents.

The research aimed to identify the importance of the use of personal protective equipment in the area of construction because it has a reputation for having a high rate of occupational accidents 
in relation to other areas, as well as to analyze all existing risks and factors. so that there can be prevention and thus map out all existing risk factors so as to be able to take appropriate measures as to the presence of such risks and to minimize or even eliminate or preserve the physical integrity of the employee regarding his activity.

Construction activity is responsible for many work-related injuries as it requires workers to be exposed to weather and risk factors such as height, drop and projection of materials, repetitive stresses, electricity, heat, often in inappropriate circumstances or in poor working conditions.

\section{BIBLIOGRAPHIC REFERENCE}

The concept defined by Social Security Law 8.213 of July 24, 1991 states, in Chapter II, Section I, Article 19:

Accident at Work is what occurs in the exercise of work in the service of the company, or in the work of the insured persons referred to in item VII of article 11 of this Law, causing bodily injury or functional disturbance that causes death or loss or permanent reduction. or temporal ability to work.

According to [1] the concept of occupational accident can be approached both in the legal as well as preventive technique.

Accident at work in the legal sphere is the one that occurs by the exercise of work, or in the service of the company, causing personal injury, functional disturbance or illness, which causes death or loss, or permanent or temporary reduction of work ability. The injury is characterized by physical-anatomical or even psychic damage. Functional disturbance causes not always visible physiological or psychic damage related to specific organs or functions. Already the disease is characterized by the morbid state of disturbance of physical or mental health, with specific symptoms in each case.

An incident can be defined as an unwanted or unplanned event that will deteriorate or decrease the company's operational efficiency. From a preventive technical standpoint, an accident is an unwanted event that results in an injury or illness to a worker or damage to property.

By taking the necessary steps to prevent and control incidents, we are protecting the physical safety of employees, equipment, materials and the environment.

Risk and danger are also other concepts that should be fixed in the existing relationship the direct definition between risk and danger when talking about safety and health at work. So we can define:

Risk is the combination of the probability and the consequence (s) of the occurrence of a particular hazardous event (represents the probability of the hazard materializing). This probability, which gives the risk a dynamic character, can be:

- High: damage will always or almost always occur;

- Average: damage will occur on some occasions;

- Low: Damage will occur rarely.

The concept of risk includes the probability of occurrence of a natural event and the appreciation by man of the causes from their harmful effects.

Hazard is a Source or situation with the potential for harm in terms of injury or injury to the human body or damage to health, property, the workplace environment, or a combination of the two. In other words, every risk is an uncontrolled danger.

\section{II.1 CAUSE OF WORK ACCIDENTS}

To avoid accidents we must know the causes that occur by the occurrence of the sum of unsafe acts and unsafe conditions in the environment. In most accidents at work, it happens due to the influence of men's behavior, social environment, personality, education, among other characteristics. According to [2] everything originates from man and the environment.

For decades, the cause of accidents has been grouped into two basic categories: Unsafe conditions and unsafe acts. However, such grouping has relevance for didactic purposes, given the processes too simple and, therefore, insufficient for the effective perception of the problem.

Unsafe workplace conditions according to [2] are those that compromise safety, ie failures, defects, technical irregularities, lack of safety device, clutter, etc. that endangers the physical integrity or health of the worker.

Unsafe conditions at workplaces are those that include worker safety. It is the failures, defects, technical irregularities and lack of safety devices that endanger the physical integrity and health of people and the safety of installations and equipment. It should be borne in mind that these should not be confused with the risks inherent in certain industrial operations. For example: Electric current is an inherent risk for work involving electricity, electrical appliances, or electrical installations. Electricity cannot be considered an unsafe condition because it is dangerous. Poorly made or improvised installations, exposed wires, etc., are unsafe conditions, electricity itself, not some examples of better known unsafe conditions; Lack of protection in machinery and equipment; Deficiency of machinery and tooling; Dangerous passages; Inadequate or defective protections; Poor housekeeping / lack of cleanliness; Defects in buildings; Inadequate lighting; Damaged floor; Risk of fire or explosion; Improper or defective electrical installations; Lack of personal protective equipment; High noise level.

In order to avoid unsafe workplace conditions the company plays a very important role as it is through the safety technicians, caregivers and supervisors who should analyze these conditions before the accident occurs and take the appropriate actions to correct it.

Through these indicators, companies can take various steps to avoid unsafe workplace conditions. These are quick and easy actions that will lead to reduced accidents.

It is the way people consciously or unconsciously expose themselves to accident risks. These are the acts responsible for many of the accidents at work and are present in most cases where someone is injured.

It is noted that in accident investigations, some unsafe acts stand out among the cataloged as frequent, although this greater evidence varies from company to company. It is noteworthy that an untrained employee who is unaware of the risks inherent in a particular activity should not be classified as an unsafe act, but rather as an unsafe condition, examples of more well-known unsafe acts: Being with or under suspended loads, Using machines without enable or allow, Lubricate, adjust and clean moving machine. Disable safety devices. Use of inappropriate clothing. Carry or stack unsafe. Try to save time Expose body parts to moving parts of machinery or equipment. Print speeding. Improvise or misuse the required task. Do not use PPE. Improper handling of chemicals. Smoking in a forbidden place. Consume drugs or alcohol during the workday. 
Accident prevention are techniques to prevent them, which should not only be observed after the accident aiming at the consequences and not the causes of the accident, because more than $96 \%$ of accidents are caused by misbehavior, thus being the largest The concern should be the worker, so when the accident prevention program is applied in the company, it is exclusively for the reduction of accidents and to anticipate the action. No need to wait for the accident to occur first and then take appropriate action, as it can lead many workers to die.

Among the main causes of occupational accidents in the country are: the lack of awareness among entrepreneurs and workers about the importance of preventing work misfortunes; extended working hours; inadequate vocational training; long periods of cumbersome and stressful transportation; improper and insufficient nutrition; provision of unhealthy service on working hours intended for normal activities; large numbers of workers without proper registration as employees; high labor turnover and abuse in outsourcing services [3].

[4] understands that the best way to prevent accidents is to eliminate unsafe acts and conditions in the workplace. Preventive measures suggested by [5] include: eliminating unsafe acts through professional selection, appropriate medical examinations, training, internal communication, and positive reinforcement; and eliminate unsafe conditions by mapping hazardous areas, in-depth accident analysis and unrestricted senior management support. The legislation also lists several programs related to accident prevention, among them:

- SSP (Social Security Profile) - which contains all the functional history, the description of the activities performed, the risks involved, the protective equipment offered by the company, etc. Its completion and delivery are mandatory at the time of the employee's dismissal from the company.

- WECP - Work Environment Control Program, must comply with the requirements contained in [10] NR 9 - Industrial Risk Prevention Program "), methods and techniques are applied to recognize, assess and control the risks encountered in this work activity. measures to eliminate or minimize and control these risks through collective or individual protection measures.

- RPP - Respiratory Protection Programs. Implementation and mandatory maintenance according to Mte Normative Instruction 01/94.

- OHMCP (Occupational Health Medical Control Program) - Regulatory Standard 7 establishes the objective of the Occupational Medical Control Program (PCMO) as the objective of "promoting and preserving the health of all its workers".

- ERP - Environmental Risk Prevention Program was established by the Occupational Safety and Health Secretariat, of the Ministry of Labor, through Regulatory Standard NR 9, Ordinance $3214 / 78$, with the purpose of defining a methodology of action to ensure the preservation of workers' health and integrity in the face of risks in the workplace. According to NR-09 of Ordinance 3.214 / 78, it is established the obligation of elaboration and implementation by all employees and institutions that admit workers as employees, of PPRA, which aims at preserving workers' health and integrity, through the anticipation, recognition, assessment and consequent control of the occurrence of environmental risks existing or that may exist in the workplace, taking into account the protection of the environment and natural resources. According to [7] NR-05 of Ordinance 3.214 / 78, the survey of environmental risks (physical, chemical, biological, ergonomic and accidents) should be performed, and these are represented in floor plan.

- HCP - Hearing Conservation Programs. According to [6] NR-01 of Ordinance $3.214 / 78$, it is up to the employer to take measures to eliminate or neutralize unhealthy and unsafe working conditions, from action levels in accordance with NR-09, levels of exposure according to [11] Annex I to NR-15 and assessment parameters according to [9] Annex I to NR-07.

- LPCP - Loss Prevention and Control Programs. Therefore, it is observed that the legislation presents programs that aim at the prevention of occupational accidents, as well as establishing norms and techniques related to occupational hygiene and safety, which must be applied with the primary purpose of protecting life.

This is not a very common practice in the construction industry, as prevention needs investment, of course it will have a very large return on reducing the accident, and when we talk about investment in construction safety entrepreneurs and building owners They often try to circumvent legislation and not follow safety standards and the way it is meant to be done.

With the techniques and studies being prepared about accident prevention, its application becomes easier. Some techniques may be applied such as near miss, task risk analysis (ART), training, safe service permit (PSS), occupational safety instruction (IST), daily safety dialogue (DDS), risk observation in the workplace. work (ORT).

These types of tools are applied in many companies, but in construction are still little used and consequently is reflected in the increased number of accidents. When entrepreneurs and builders apply these tools, accidents tend to be reduced as they require training for all employees.

On the other hand, in many cases, there is a lack of interest from the entrepreneur and builder in the application of occupational health and safety programs, which makes employees not develop the culture of accident prevention.

For Torreira (1999) it is necessary to follow the following measures for the prevention of accidents:

a) Replace certain materials with others that may be less hazardous;

b) Effectively train the worker regarding safety procedures and practices;

c) Teach and insist on how best to do the job safely;

d) Establish rules of use and care that must be followed when using a certain product with the corresponding safety.;

e) Educate people about the dangers that may arise from improper use of a product, process or activity, and how to take appropriate protective action;

f) Train employees on recognition, hazard assessment and compliance with safety and legal liability laws;

g) Motivate people to cooperate with life-saving safety programs through effective participation.

\section{MATERIAL AND METHODS}

Occupational safety is a set of sciences and technologies that aims to promote the protection of workers in their workplace, aiming at reducing work accidents and occupational diseases. It is one of the areas of occupational safety and health whose objective is to identify, assess and control risk situations, providing a safer and healthier work environment for people. 
Work safety should always be very important to companies, whether small, medium or large, because the size of the company cannot influence the importance of safety. This importance must be considered because behind any machine there is a working man, so the employee's safety is not only linked to the injuries he may be subjected to, but there are many other factors that influence the man with the unsafe aspect. social, economic and human aspects.

Even with a low price to pay for security with training in the use of EPC, PPE, prevention techniques and the provision of the best EPC's and EPI's, there are still companies that do not give due importance, besides these companies enter the factor. employees who are not interested in their own safety and health. In the present day many of the thoughts now are others, where safety comes first, far above even production. Advantages for the company that adopts a model in Health and Safety at Work. Prevents and reduces accidents and diseases; Protects the physical and mental integrity of workers; Educates for the adoption of preventive practices; Avoids medication and prosthesis costs; Decreases absenteeism; Continuously improves work environments; Prevents damage to the company's image; Eliminates property damage; Avoids the payment of expertise, fees and legal compensation; Potentiates interpersonal relationships; Optimizes the organizational climate; Meets the requirements of the legislation; Increases productivity Increases the competitiveness of the company; Expand Your Market.

In most construction companies the safety of construction work is of little importance as they believe it is unnecessary to invest heavily. Thus the company and the employee are harmed, because there is an increase in accidents resulting in the removal of the employee who is out of work, may even become invalid or in the worst case lose his life.

There is a great difficulty in implementing work safety, especially from the employee's perception, who often do not consider safety instructions as important, do not understand the procedures given, find it uncomfortable and not very important not to follow the instructions. safety standards, the use of PPE, and therefore disrespect them, thus contributing to the increase in the number of accidents.

In order to reduce this accident it is necessary to carry out an education and training work with the collaborator regarding its safety. This education is delivered through lectures, training, and awareness, but these presentations cannot be done irrepressibly, not as an obligation to safety, but as awareness for the employee. This way the employee will feel safer with the information and not treating security as a burden.

Social factors should also be considered as low wages, which lead employees to eat poorly, facilitating the contagion and contamination of occupational diseases. Often public transport is inadequate, or even the distance from the workplace makes the employee have to wake up early to commute to work.

There are many inputs that expose employees to the risks of accidents such as: Lack of personal protective equipment or misuse of them; Lack of collective protection equipment; Long working hours; Lack of training; Inadequate installations; There is a profile of insensitivity to occupational hygiene and safety. The most infringed items - sanitary conditions and PPE - are those with the highest number of irregularities, so they are items that everyone knows about and do not depend on any deeper technical knowledge.
According to the Ministry of Labor (MTE), in [8] NR 6 of Ordinance 3.215 defines Personal Protective Equipment - PPE any device of individual use, domestic or foreign, designed to protect the health and physical integrity of the worker.

PPE is equipment for personal and personal use and represents a resource when a more effective control that would lead to the elimination of risks to occupational accidents is impossible [13].

For [13] PPE should only be used in the following cases:

- In an emergency, when the work routine is broken by any abnormality;

- In periods of non-routine repair, maintenance or installation;

- When the worker is directly exposed to a risk that cannot be controlled by technical safety devices.;

- When risk exposure is only partially controllable.

In accordance with NR 6, the company is required to provide employees with risk-free PPE free of charge, in perfect repair and operation, under the following circumstances:

a) where collective protection measures are technically infeasible or do not offer complete protection against the risks of occupational accidents and / or occupational and occupational diseases.;

b) While collective protection measures are being implemented;

c) to respond to emergency situations.

Personal protective equipment of national or imported manufacture may only be offered for sale or used with the indication of the Certificate of Approval (CA) issued by the National Agency for Safety and Health at Work of the MTE.

There are some myths that no longer serve as an excuse not to wear PPE's, they are uncomfortable, really PPE's were very uncomfortable in the past, but nowadays there are PPE made of light and comfortable materials. The feeling of discomfort is associated with factors such as lack of training and misuse, the employee does not "like" to wear PPE. The worker refuses to use PPE only when he is not aware of the risk and the importance of protecting his health. . The professional requires the PPE's to work. Eg in the 1980s almost nobody wore seat belts in cars, today most drivers wear and recognize the importance.

This disinterest or refusal occurs mainly when the worker only receives personal protective equipment without any instruction on how and why to use it.

Sometimes PPE becomes uncomfortable when worn or the work pace is slowed by the use of protective equipment. It also happens that the immediate bosses turn a blind eye and even encourage work without the use of personal protective equipment, thinking only about the importance of production, without worrying about the considerable risks or occupational diseases associated with the worker. In fact most of the time these people have no knowledge about the paramount importance of using PPE and act this way.

\section{STUDY APPLICATION}

For this phase of the work was visited a construction in Manacapuru metropolitan region of Manaus. With site visit and inspection with visual assessment, annotations, photographic report, questionnaire applied to workers. 
During the visits, certain personal protective equipment was considered, the ones most used and mentioned by the workers. For example: safety helmet which is a rigid device used to protect the head or parts of it from impact; hearing protector that protects against high noise levels; safety gloves that protect against cuts, electric shocks, radiation, etc .; safety goggles and face shields that are intended to protect the eyes and faces against miscellaneous particles, light, solar radiation, etc .; safety boots for the protection of feet and legs against sharps, moisture from water operations; and seat belts to prevent falls from working at heights.

The workers approached showed willingness to answer the questions of the questionnaire, even not knowing the answer most of the time sought to justify them. No rejection was noticed because of the quality of the PPE, but because of the type of discomfort caused by: helmets heat the head; gloves slip, belt restrains movement, boots make feet sweat, among others, causing justified withdrawal in some circumstances.

Table 1: Summary of the questionnaire applied according to Workers answers.

\begin{tabular}{|c|c|}
\hline Knowledge & $100 \%$ know what PPE is \\
\hline Importance & $\begin{array}{l}100 \% \text { know the importance of using } \\
\text { PPE }\end{array}$ \\
\hline Required use & $\begin{array}{l}80 \% \text { know PPE's are mandatory for } \\
\text { their }\end{array}$ \\
\hline Orientation / Training & $\begin{array}{l}70 \% \text { say they do not use for lack of } \\
\text { training and have no education to use }\end{array}$ \\
\hline Utilization & $\begin{array}{l}75 \% \text { say they stop using somewhere } \\
\text { time }\end{array}$ \\
\hline Accidents at work & $90 \%$ never had accidents \\
\hline Prevention & $\begin{array}{l}100 \% \text { consider PPE as a form of } \\
\text { Prevention }\end{array}$ \\
\hline Nuisance & $85 \%$ say that the PPE Nuisance \\
\hline Correct form of use & $\begin{array}{l}55 \% \text { say their peers don't use it } \\
\text { Correct }\end{array}$ \\
\hline PPE Quality & $\begin{array}{l}45 \% \text { say they need to improve the } \\
\text { material of the }\end{array}$ \\
\hline
\end{tabular}

Source: Authors, (2019).

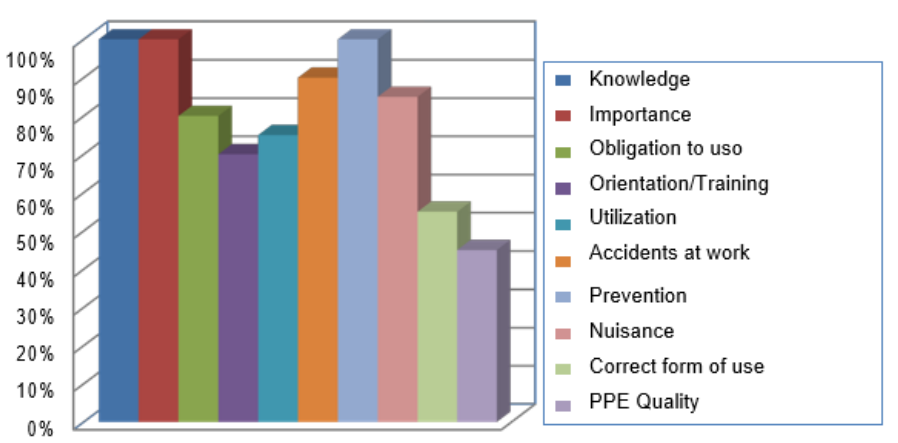

Figure 1: Graph of questionnaire summary applied according to Workers' answers.

Source: Authors, (2019).

During the visit, 25 workers were approached, such as: construction worker, sharpener, bricklayer, carpenter, janitor, welder, warehouse worker, electrical technician, noting whether or not they were using their personal protective equipment correctly, passing Thus the interview based on the questionnaire that prioritized the following questions: mandatory use, knowledge, importance, orientation, use, work accidents, training, discomfort and quality of personal protective equipment.

\section{RESULTS AND DISCUSSION}

The workers consulted presented factors that contribute favorably or unfavorably to the proper use of PPE at the construction site.

Not all workers interviewed use the provided PPEs correctly, but remove them on occasions that they should not, because they are uncomfortable and there is no initial awareness or lack of constant surveillance during work on the jobsite. With the misuse and poor hygiene of PPE some equipment that would still have a considerable useful life is destroyed before time, and when they take off they do not know where they put it.

It is worrying to know that $70 \%$ do not use personal protective equipment because they do not have this habit and safety education, either by forgetfulness or because it bothers figure 2.

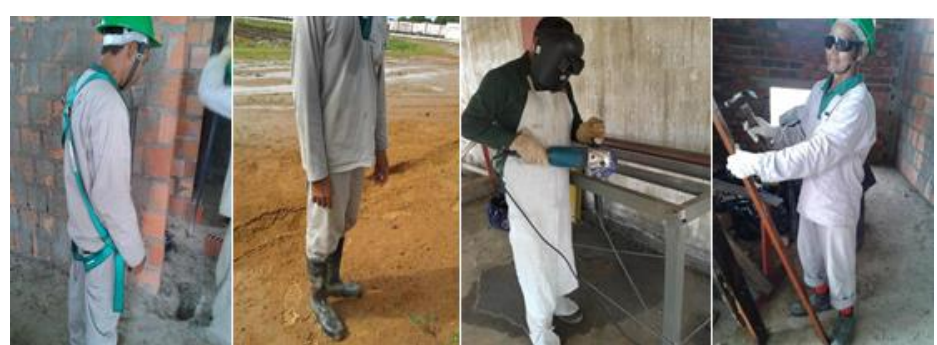

Figure 2: Use of PPE.

Source: Authors, (2019).

From this percentage it can be observed that there is no constant supervision of the competent bodies and due collection by the company with workers when the proper use of PPE's this fact has contributed to the lack of habit of the correct use of some equipment, which take the PPE with a few hours of work and only miss hours later.

When the PPE withdrawal occurs at any time, an unforeseen accident can occur with serious consequences for the employee or others. However, by reducing these unsafe attitudes with training and lectures, the likelihood of unsafe attitudes was minimized and the safety of all was increased.

There is widespread concern that $85 \%$ of respondents say that personal protective equipment bothers and irritates causing irritation and discomfort which is why the personal protective equipment is removed. Once again demonstrates the need for greater and better enforcement.

\section{FINAL CONSIDERATIONS}

Protecting the employee's physical integrity and health is not isolated behavior. It involves the perception of the environmental risks of work, a process of constant training, education and awareness, with investments in material resources and people, a strategic planning to make more effective preventive actions. It also involves the participation and especially the commitment of the workers, essential elements for the success of this great responsibility of the parties, where all aspects related to PPE are highly relevant. 
Simply providing personal protective equipment will never be able to protect the health of the worker and prevent contamination. Incorrectly used PPE can further compromise worker safety. Developing risk perception combined with a set of safety information and ground rules is believed to be the most important tools to prevent exposure and to ensure the success of individual worker health protection measures.

The correct use of PPE is a rapidly evolving topic and requires continuous retraining of occupational safety professionals through training and access to up-to-date information.

Based on the answers obtained from the questionnaire applied to workers, it can be seen that the lack of safety information and awareness and the ergonomics of personal protective equipment are the main reasons for resistance to its proper use, which causes non-use. Or withdrawal at some point from work. This unsafe act can cause accidents, serious or not, but accidents that generate inconvenience to all.

Therefore, it found some efficient measures that can be taken to avoid or decrease the rates of accidents in the construction industry, such as: lectures and training, aiming to raise workers' awareness of the importance and correct use of PPE, thus reducing the likelihood of occurrence. Accidents and consequently increasing the safety of all.

\section{REFERENCES}

[1] Oliveira, Sebastião Geraldo de. Estrutura normativa da segurança e saúde do trabalhador no Brasil. Estrutura normativa da segurança e saúde do trabalhador no Brasil, 2007.

[2] Zócchio, Alvaro. Prática da prevenção de acidentes. ABC da segurança do trabalho. São Paulo: Atlas, 2002.

[3] Ayres, Denis de Oliveira e Corrêa, José Aldo Peixoto. Manual de Prevenção de Acidentes de Trabalho. São Paulo: Aspectos Técnicos e Legais, 2001.

[4] Alves, Everton Fernando. Programas e ações em qualidade de vida no trabalho. InterfacEHS-Revista de Saúde, Meio Ambiente e Sustentabilidade, 2011, 6.1: 60-78.

[5] Oliveira, Patrick Rafael de. A Importância de EPI' S Nas Empresas Quimícas. 2017.

[6] NR 1- Disposições Gerais. Available in: <http://portal.mte.gov.br/data/files/FF8080812BE914E6012BEF 0F7810232C/nr_01_at.pdf >.

[7] NR 5 - Comissão Interna de Prevenção de Acidentes. Available in: <http://portal.mte.gov.br/data/files/FF8080812BE914E6012BEF 0F7810232C/nr_01_at.pdf $>$.

[8] NR 6 - Equipamento de Proteção Individual - EPI. Available in: <http://www.mashi.com.br/NR06.PDF>.

[9] NR 7- Programa de Controle Médico de Saúde Ocupacional. Available

<http://www.guiatrabalhista.com.br/legislacao/nr/nr7.htm>.
[10] NR 9 - Programa de Prevenção de Riscos Ambientais. Available in <http://portal.mte.gov.br/data/files/FF8080812BE914E6012BEF 1CA0393B27/nr_09_at.pdf $>$.

[11] NR 15 - Atividades e Operações Insalubres. Available in: <http://portal.mte.gov.br/data/files/8A7C816A36A27C140136A 8089B344C39/NR-

15\%20\%28atualizada\%202011\%29\%20II.pdf>.

[12] NR 18 - Condições e Meio Ambiente de Trabalho na Indústria da Construção. Available in: <http://portal.mte.gov.br/data/files/8A7C812D3226A41101323B 2D85655895/nr_18.pdf $>$.

[13] Oliveira, A.; Pilon, V. Avaliação dos fatores intervenientes no uso dos EPIs pelos trabalhadores da construção. In.: Simpósio Brasileiro de Gestão e Economia da Construção, 3., 2003, São Carlos. Anais ... São Carlos: SIBRAGEC, 2003. 